\title{
Statin use in COPD patients is associated with a reduction in mortality: a national cohort study
}

\author{
*Carlene MM Lawes ${ }^{\mathrm{a}}$, Simon Thornley ${ }^{\mathrm{b}}$, Robert Young ${ }^{c}$, Raewyn Hopkins ${ }^{c}$, \\ Roger Marshall ${ }^{b}$, Wing Cheuk Chan ${ }^{\text {, }}$, Gary Jackson ${ }^{\mathrm{e}}$
}

\author{
${ }^{a}$ Clinical Trials Research Unit, University of Auckland, Auckland, New Zealand \\ b Section of Epidemiology and Biostatistics, University of Auckland, Auckland, New Zealand \\ ' Schools of Medicine and Biological Sciences, University of Auckland, Auckland, New Zealand \\ ${ }^{d}$ Counties Manukau District Health Board, Manukau City, New Zealand \\ e Health Partners Consulting Group, Auckland, New Zealand
}

Received 2nd May 2011; resubmitted 14th July 2011; revised 22nd August 2011; accepted 9th September 2011; online 4th January 2012

\begin{abstract}
Aims: To assess whether statin use is associated with reduced mortality in patients with chronic obstructive pulmonary disease (COPD).

Methods: Hospitalisation, drug dispensing, and mortality records were linked for New Zealanders aged 50-80 years discharged from hospital with a first admission with COPD in 2006. Patients were classified according to whether or not they were prescribed statins prior to admission. Baseline characteristics were compared and hazard ratios calculated for statin users versus statin non-users for all-cause mortality over follow-up of up to 4 years.

Results: A total of 1,687 patients (mean age 70.6 years) were followed, including 596 statin users and 1,091 non-users. There were more men in the statin user group (58.4\% vs. $48.5 \%$ ), and statin users were more likely to have a history of cardiovascular disease (58.6\% vs. $25.1 \%)$, prescription for frusemide as a proxy for heart failure $(47.7 \%$ vs. $24.5 \%)$ or diabetes (35.4\% vs.11.6\%) than statin non-users $(p<0.001)$. A total of 671 deaths occurred during the follow-up period. After adjustment for age, sex, ethnic group, history of cardiovascular disease, diabetes, and prescription for frusemide, the hazard ratio for statin users vs. statin non-users for all-cause mortality was 0.69 (95\% Cl 0.58 to 0.84).

Conclusions: Statin use is associated with a 30\% reduction in all-cause mortality at 3-4 years after first admission for COPD, irrespective of a past history of cardiovascular disease and diabetes.

(C) 2012 Primary Care Respiratory Society UK. All rights reserved.

CMM Lawes et al. Prim Care Respir J 2012; 21(1): 35-40

http://dx.doi.org/10.4104/pcrj.2011.00095
\end{abstract}

Keywords COPD, mortality, statins, epidemiology, observational study

See linked editorial by Pearson on pg 5

\section{Introduction}

Chronic obstructive pulmonary disease (COPD) is the fourth leading cause of death in New Zealand (total population 4.4 million), and is ranked second in men and seventh in women for years lost to disability. ${ }^{1-3}$ Aside from smoking cessation and use of oxygen in patients with severe disease, current therapeutic interventions only modify symptoms, with little evidence to indicate that they positively affect disease progression. ${ }^{4-7} \mathrm{New}$ therapies are needed to improve prognosis and quality of life and to reduce mortality for people with this condition. ${ }^{8,9}$
Statins (HMG-CoA reductase inhibitors) lower plasma cholesterol and are used as part of the prevention and management of cardiovascular disease (CVD). However, laboratory-based and animal research has shown that statins have a diverse range of 'pleiotropic effects' including antiinflammatory actions, anti-thrombotic properties, anti-oxidant effects, and immunomodulatory effects. ${ }^{10-13}$ Recent evidence suggests that statins reduce pulmonary inflammation and may suppress the inflammation associated with cigarette smoke and ameliorate the associated structural and functional abnormalities in the lung. ${ }^{12,14}$ It is therefore possible that these effects may result in therapeutic benefits in patients with COPD over and

\footnotetext{
* Corresponding author: Dr Carlene MM Lawes, Clinical Trials Research Unit, University of Auckland, Private Bag 92019 Auckland, Auckland 1142, New Zealand. Tel: +64 93737599 E-mail: c.lawes@ctru.auckland.ac.nz
} 
above reducing their risk of CVD.

Seven published observational studies have shown that statin use is associated with beneficial effects for COPD patients for a number of different outcomes including COPD- and non-COPDrelated mortality and COPD exacerbations. ${ }^{15-21}$ The majority of these studies are based on one or a limited number of sites, and they vary in terms of their sample size, study population, followup, and analytical methods. Despite their heterogeneity, they consistently report benefit from statin use ${ }^{22,23}$ and show clinically meaningful mortality and morbidity reduction in metaanalyses. ${ }^{22,24}$ To our knowledge, no previous analyses have been undertaken at a national level. We therefore used national data to assess whether statin use is associated with reduced mortality in patients with COPD in New Zealand.

\section{Methods}

\section{Data collection}

We identified all patients aged between 50 and 80 years inclusive who were admitted to a New Zealand public hospital during 2006 with a first primary hospital discharge code consistent with COPD (ICD-10 codes J43 to J44) and who were discharged alive. Where an individual had had multiple discharges in 2006, the first COPD discharge was considered to be the index event. Using the National Health Index (NHI) number, a unique patient identifier used throughout the New Zealand health system, we linked these national hospital discharge data with mortality and drug dispensing databases for the study population. Statins are only available on prescription in New Zealand, all are subsidised, and prescriptions redeemed at pharmacies are recorded. The reliability of such data has increased substantially since 2006 and more than $90 \%$ of claims are linked to an $\mathrm{NHI}$ number.

The cases were divided into two groups based on statin use prior to hospital admission: statin users (those redeeming prescriptions for statins in the 6 months prior to hospitalisation) and statin non-users (those with no prescriptions redeemed for statins in the 6 months prior to hospitalisation). Demographic variables (age, sex, ethnicity, and socioeconomic status) were obtained on each participant from the NHI record. Ethnic group was self-identified and derived from primary healthcare enrolment records and was prioritised in the following order: Maori (indigenous New Zealanders), Pacific, South Asian, and Other (predominantly New Zealand European). Other variables included: past history of CVD (admission with CVD or outpatient CVD procedures in the last 5 years, or prescriptions redeemed for medications for coronary heart disease, specifically glyceryl trinitrate, isosorbide dinitrate, isosorbide mononitrate, nicorandil, or perhexiline in the 6 months prior to COPD admission); a past history of diabetes (admission with diabetes in the last 5 years, or dispensing of oral hypoglycaemic drugs or insulin in the 6 months prior to COPD admission); any dispensing of $\beta$-blockers in the 6 months before admission; and whether patients were currently undergoing cancer treatment - i.e. chemotherapy or radiotherapy (recorded in the hospital procedure records) as an outpatient in the last 5 years). A prescription redeemed for frusemide in the last 6 months was used as a proxy for a past history of heart failure or cor pulmonale.

It was not possible to ascertain COPD severity accurately from the available databases as no clinical measures such as spirometry were included. However, to restrict heterogeneity (or confounding) by disease severity, we selected only those cases with first ever admission with COPD over the 5 -year period up to 2006. Reliable data were not available on smoking status in 2006.

The study outcome of interest was time to death from any cause over a maximum follow-up period of 4 years from the date of hospital discharge during 2006 until 18 January 2010 (median follow-up 2.3 years; interquartile range $0.6-3.3$ years). Any person with no recorded death was assumed to be still alive at 18 January 2010 and considered to have a censored survival time on this date.

\section{Statistical analysis}

Cox proportional hazard regression was used to estimate the hazard ratio for the exposure of interest (statin treatment). Age, ethnic group, and sex were force fitted into the model. Socioeconomic status, chemotherapy or radiotherapy treatment, diabetes, history of CVD, other medications, and frusemide use were assessed as confounders if inclusion in the model changed the beta coefficient for the exposure of interest by more than $10 \%$.

Proportional hazards assumptions were assessed using the $\mathrm{R}$ function cox.zph which calculates tests of the proportional hazards assumption for each covariate by correlating the corresponding set of scaled Schoenfeld residuals with a suitable transformation of time based on the Kaplan-Meier estimate of the survival function. Stratification was used to allow different baseline hazards for exposure groups where the proportional hazards assumption appeared not to hold. Interactions between statin use, CVD history, and frusemide were tested. Few data are missing in routinely collected datasets so complete case analysis was calculated. Because patients who were treated with statins were likely to have more co-morbidities and adverse prognostic features than those who were not, propensity scoring ${ }^{25}$ with closest unit matching was used to check the validity of the Cox regression. We adjusted for matched pair effects in the Cox model of propensity matched subjects. The R project was used for all analyses. ${ }^{26}$

\section{Results}

A total of 1,687 patients were identified who had been admitted to any public hospital in New Zealand during 2006 and who had a discharge diagnosis of first episode of COPD (Table 1). This included 596 statin users and 1,091 statin non-users, giving the frequency of statin use among COPD patients hospitalised with exacerbations of $35 \%$. There were more men in the statin users 


\begin{tabular}{|c|c|c|c|}
\hline \multirow[t]{2}{*}{ Characteristics } & \multicolumn{3}{|l|}{ Statin use } \\
\hline & $\begin{array}{l}\text { No } \\
(n=1,091)\end{array}$ & $\begin{array}{l}\text { Yes } \\
(n=596)\end{array}$ & $\begin{array}{l}\text { Total } \\
(n=1,687)\end{array}$ \\
\hline \multicolumn{4}{|l|}{ Gender } \\
\hline Female & $562(51.5 \%)$ & $248(41.6 \%)$ & $810(48.0 \%)$ \\
\hline Male & $529(48.5 \%)$ & $348(58.4 \%)$ & $877(52.0 \%)$ \\
\hline \multicolumn{4}{|l|}{ Age (years) } \\
\hline $50-59$ & $167(15.3 \%)$ & $45(7.6 \%)$ & $212(12.6 \%)$ \\
\hline $60-69$ & $331(30.3 \%)$ & $197(33.1 \%)$ & $528(31.3 \%)$ \\
\hline $70-79$ & $593(54.4 \%)$ & $354(59.4 \%)$ & $947(56.1 \%)$ \\
\hline Median age (years) & 70.1 & 71.6 & 70.6 \\
\hline \multicolumn{4}{|l|}{ Ethnicity } \\
\hline Other & $815(74.7 \%)$ & $460(77.2 \%)$ & $1275(75.6 \%)$ \\
\hline Maori & $219(20.1 \%)$ & $99(16.6 \%)$ & $318(18.9 \%)$ \\
\hline Pacific & $53(4.9 \%)$ & $31(5.2 \%)$ & $84(5.0 \%)$ \\
\hline South Asian & $4(0.4 \%)$ & $6(1.0 \%)$ & $10(0.6 \%)$ \\
\hline \multicolumn{4}{|c|}{ NZDep06 deprivation quintile* } \\
\hline $\begin{array}{l}1 \text { and } 2 \text { (least } \\
\text { deprived) }\end{array}$ & $76(7.3 \%)$ & $47(8.2 \%)$ & $123(7.6 \%)$ \\
\hline 3 and 4 & $143(13.8 \%)$ & $71(12.4 \%)$ & $214(13.3 \%)$ \\
\hline 5 and 6 & $177(17.1 \%)$ & $97(16.9 \%)$ & $274(17.0 \%)$ \\
\hline 7 and 8 & $305(29.5 \%)$ & $149(26.0 \%)$ & $454(28.2 \%)$ \\
\hline $\begin{array}{l}9 \text { and } 10 \text { (most } \\
\text { deprived) }\end{array}$ & $334(32.3 \%)$ & $210(36.6 \%)$ & $544(33.8 \%)$ \\
\hline History of CVD & $274(25.1 \%)$ & $349(58.6 \%)$ & $623(36.9 \%)$ \\
\hline History of diabetes & $127(11.6 \%)$ & $211(35.4 \%)$ & $338(20.0 \%)$ \\
\hline Dispensed frusemide & $267(24.5 \%)$ & $284(47.7 \%)$ & $551(32.7 \%)$ \\
\hline Dispensed $\beta$-blocker & $124(11.4 \%)$ & $224(37.6 \%)$ & $348(20.6 \%)$ \\
\hline $\begin{array}{l}\text { Undergoing cancer } \\
\text { treatment }\end{array}$ & $112(10.3 \%)$ & $86(14.4 \%)$ & $198(11.7 \%)$ \\
\hline Death during follow-up & $429(39.3 \%)$ & $242(40.6 \%)$ & $671(39.8 \%)$ \\
\hline \multicolumn{4}{|c|}{ Data presented as $n(\%)$ except for median age which is presented in years } \\
\hline \multicolumn{4}{|c|}{$\begin{array}{l}\text { *NZDep06 is a census-based small area index of deprivation with a relative } \\
\text { deprivation score assigned to each mesh block (containing a median of } \\
\text { approximately } 90 \text { people) in New Zealand. It combines nine variables from the } \\
2006 \text { Census reflecting eight dimensions of deprivation including income, home } \\
\text { ownership, employment, and qualifications. Seventy-eight individuals had } \\
\text { missing deprivation status. }\end{array}$} \\
\hline$C V D=$ cardiovascular diseas & & & \\
\hline
\end{tabular}

group than in the statin non-user group (58.4\% vs. $48.5 \%$, $\mathrm{p}<0.001$ ), and the statin user group was also more likely to have a history of CVD ( $58.6 \%$ vs. $25.1 \%, p<0.001)$, to be prescribed frusemide $(47.7 \%$ vs. $24.5 \%, p<0.001)$, or to have a history of diabetes $(35.4 \%$ vs. $11.6 \%, p<0.001)$ in the previous 5 years.

Within the statin user group, $91 \%$ (545/596) were prescribed simvastatin and 9\% (55/596) were prescribed atorvastatin, with four individuals having both agents before admission. Of those in the statin user group, 528 (89\%) had a further prescription redeemed for statins in the 6 months after discharge compared with $89(8.2 \%)$ in the statin non-user group.

During the 3-4-year follow-up period there were 671 deaths (about $40 \%$ of all participants). Similar proportions of deaths occurred among statin users (40.6\%, 242 deaths) and among
Figure 1. Cox modelled survival plot of statin users vs. statin non-users for those receiving cancer treatments and not receiving cancer treatments*

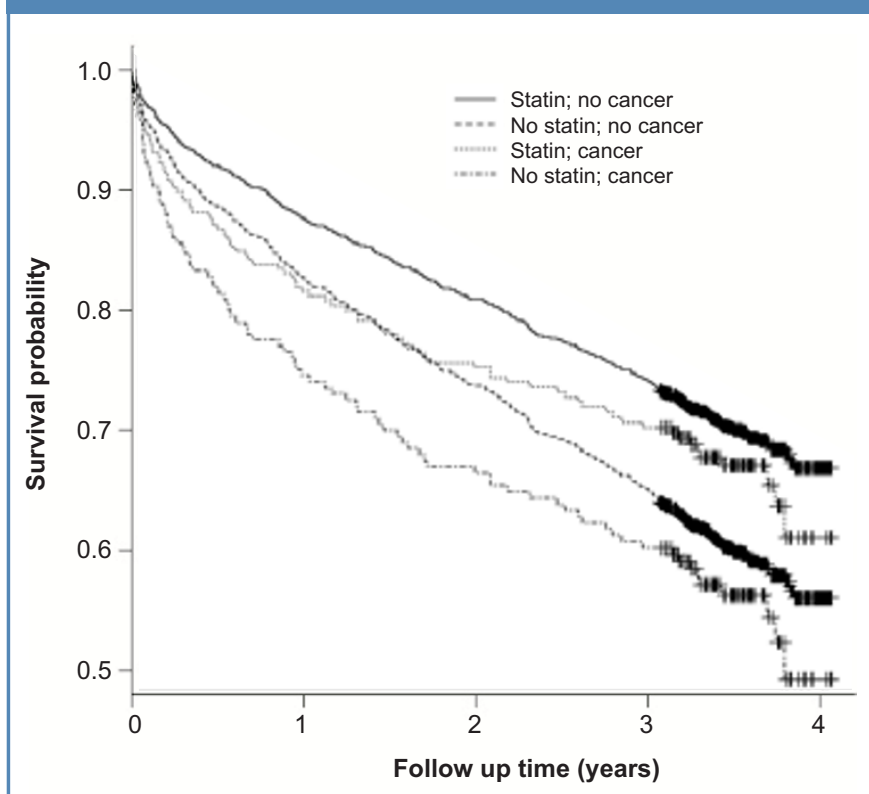

*The adjusted Cox-modelled survival plot for those treated with statins and those not treated, for the two strata of the model; treatment or no treatment for cancer. All other covariates are averaged over the population. The plot is adjusted for potential confounders such as age, sex, ethnicity, co-morbidities. The vertical lines at the end of each data line are censoring points. They exist because participants entered into the study at various time points during 2006. However, all follow-up ceased at the same date on the 18 January 2010. Therefore the follow-up duration for each individual varied depending on when exactly they entered the study.

those not using statins (39.3\%, 429 deaths). Cause of death was only available for 376 of the 671 deaths (56\%) because of a delay in coding, e.g. due to coroner's cases where cause of death is initially uncertain. Of the deaths with a disease classification, $137(36 \%)$ were attributed to COPD (ICD codes J43 to J44), 69 (18\%) to heart disease (ICD codes I20 to I50), 11 (3\%) to stroke (ICD codes 160 to 169), and 45 (12\%) to lung cancer. The remaining 30\% of these deaths were due to other causes.

An adjusted Cox-modelled survival plot for statin versus nonstatin use is shown in Figure 1 for the two strata of the model: those receiving treatment for cancer and those not receiving cancer treatment. The graph depicts the non-proportional survival between the two strata and shows poorer survival among the non-statin group (covariates were averaged over the population). This analysis is adjusted for potential confounders. After adjustment for age, sex, ethnicity, history of CVD, diabetes, prescription for $\beta$-blockers, prescription for frusemide (as a proxy for heart failure), the hazard ratio (HR) for statin users versus statin non-users in Cox's proportional hazards model was 0.69 (95\% confidence intervals (CI) 0.58 to 0.84 ) (Table 2). Covariate HRs did not change significantly with time, except for cancer treatment. For this reason, the model was stratified by this 


\begin{tabular}{|c|c|c|}
\hline Characteristics & $\begin{array}{l}\text { Unadjusted* } \\
\text { HR }(95 \% \mathrm{Cl})\end{array}$ & $\begin{array}{l}\text { Adjustedt } \\
\text { HR }(95 \% \mathrm{Cl})\end{array}$ \\
\hline Male gender & $1.32(1.13$ to 1.53$)$ & $1.20(1.02$ to 1.40$)$ \\
\hline \multicolumn{3}{|l|}{ Age (years) } \\
\hline $50-59$ & Ref & Ref \\
\hline $60-69$ & $1.77(1.28$ to 2.45$)$ & $1.65(1.18$ to 2.31$)$ \\
\hline $70-79$ & $2.50(1.85$ to 3.39$)$ & $2.22(1.60$ to 3.07$)$ \\
\hline \multicolumn{3}{|l|}{ Ethnicity } \\
\hline Other & Ref & Ref \\
\hline Maori & $0.93(0.77$ to 1.14$)$ & $1.04(0.84$ to 1.29$)$ \\
\hline Pacific & $0.77(0.53$ to 1.13$)$ & $0.84(0.57$ to 1.25$)$ \\
\hline South Asian & $0.71(0.23$ to 2.20$)$ & $0.77(0.24$ to 2.40$)$ \\
\hline \multicolumn{3}{|c|}{ NZDep06 deprivation quintile* } \\
\hline $\begin{array}{l}1 \text { and } 2 \text { (least } \\
\text { deprived) }\end{array}$ & Ref & Ref \\
\hline 3 and 4 & $0.94(0.66$ to 1.34$)$ & $1.03(0.72$ to 1.46$)$ \\
\hline 5 and 6 & $1.02(0.73$ to 1.43$)$ & $1.07(0.76$ to 1.49$)$ \\
\hline 7 and 8 & $0.96(0.70$ to 1.31$)$ & $1.00(0.73$ to 1.37$)$ \\
\hline $\begin{array}{l}9 \text { and } 10 \text { (most } \\
\text { deprived) }\end{array}$ & 0.97 (0.71 to 1.32$)$ & $1.06(0.78$ to 1.46$)$ \\
\hline History of CVD & $1.58(1.36$ to 1.84$)$ & $1.46(1.24$ to 1.73$)$ \\
\hline History of diabetes & $1.09(0.91$ to 1.31$)$ & $1.03(0.84$ to 1.26$)$ \\
\hline Dispensed frusemide & $2.10(1.80$ to 2.44$)$ & 1.94 (1.64 to 2.28$)$ \\
\hline Dispensed $\beta$-blocker & $1.24(1.04$ to 1.49$)$ & $1.01(0.84$ to 1.23$)$ \\
\hline Dispensed statin & $1.03(0.88$ to 1.20$)$ & $0.69(0.58$ to 0.84$)$ \\
\hline \multicolumn{3}{|c|}{$\begin{array}{l}\text { †Adjusted hazard ratios using Cox proportional hazard regression were adjustec } \\
\text { for all variables included in table except socioeconomic status (NZDep06), as } \\
\text { adjusting for this variable inflated the variance and did not change the estimate } \\
\text { of the exposure of interest. }\end{array}$} \\
\hline rdiovascular dise & & \\
\hline
\end{tabular}

variable with different baseline hazards estimated for subjects treated and not treated for cancer.

We also carried out a propensity-matched analysis with a restricted dataset. Individuals were matched on the basis of the demographic and clinical characteristics associated with taking a statin, derived from a logistic model. After matching by these criteria, the number of participants was reduced to 1,192 overall, but the estimate and variance for the effect of statins on mortality (HR $0.64,95 \% \mathrm{Cl} 0.48$ to 0.86 ) was very similar to the unmatched analysis.

\section{Disaussion}

\section{Main findings}

This cohort study has produced several findings that are consistent with those of other observational studies of statin use in patients with COPD. First, statins were used by $35 \%$ of all those admitted to hospital in 2006 with COPD ${ }^{20,23}$ Second, those using statins had significantly higher rates (2-3-fold) of CVD and diabetes which might otherwise increase their mortality (confounding by co-morbidity or drug indication). ${ }^{15-21}$ Third, about $40 \%$ of patients died during the follow-up period, and nearly $50 \%$ of known deaths were attributed to COPD or lung cancer, $30 \%$ to other cancers, and only $21 \%$ to CVD. ${ }^{27}$ Lastly, a $30 \%$ lower all-cause mortality was associated with statin use after adjustment for other risk variables. These findings are consistent with other reported reductions in mortality of $30-50 \%$ in those with COPD taking statins. ${ }^{22-24}$

\section{Strengths and limitations of this study}

All cases were defined by a primary hospital discharge code for COPD. This limited the representativeness of our sample to all COPD patients; however, it did ensure that our sample was primarily defined by the disease of interest (i.e. COPD). This case definition also reduced the heterogeneity of the group in terms of disease severity, as it excluded less severe non-hospitalised COPD patients and also patients with more severe COPD with multiple previous admissions.

A weakness of the study was the lack of data on smoking status and severity of COPD (defined by spirometry). While one can assume that almost all cases would have been long-term smokers, some may have quit smoking either before or after the diagnosis, which would impact on disease progression. This is a common limitation in most of the observational studies of statins and COPD, and reflects the low priority that has historically been given to the routine collection of smoking status in hospital records. It is therefore possible that the smoking exposure and severity of COPD was lower in statin users than in non-users. This could have resulted in a 'healthy user' effect where statin users were subject to other factors that reduced their mortality. However, in an audit of COPD patients with similar demographic characteristics to the current patients, smoking status and smoking exposure were not significantly different between statin users and non-users, ${ }^{23}$ nor did spirometry results, past history of pneumonia, and history of COPD exacerbation frequencies differ between statin users and non-users. Previous observational studies that controlled for smoking status still found an overall mortality benefit among patients taking statins. ${ }^{17,20,21}$ It is therefore unlikely that confounding by COPD severity (more mild disease) or smoking history (less exposure to tobacco smoke) explained the underlying mortality benefit seen in statin users compared with non-users. A further weakness shared with all the observational studies is the lack of accurate data on actual statin usage (duration, dose, and adherence). However, poor compliance would most likely dilute - rather than spuriously generate $-a$ statin-based effect.

Consistent with other studies, ${ }^{17-21}$ statin users in this study had more co-morbid disease than non-users, specifically CVD ( $59 \%$ vs. $25 \%$ ) and diabetes ( $35 \%$ vs. $12 \%$ ), but these differences are controlled for in our analyses. In contrast to other studies, we also used the prescription of frusemide as a marker of heart failure and cardiovascular risk. Frusemide use was nearly twofold greater in statin users than in non-users (48\% vs. 25\%) and was the most important independent risk variable for mortality, exceeding that of age and history of CVD (Table 2). Despite the significantly higher rates of co-morbid diseases 
(diabetes and CVD), statin users died at the same crude rate as non-users in the unadjusted analysis (Table 1). We could not attribute this effect to any other prescribed drug, including use of $\beta$-blockers.

Although statin users have been found to have significantly more risk of CVD than non-users, there remains the possibility that factors other than those discussed above and medication use may account for the reduction in mortality in those taking statins. Further explanations for this 'healthy user' effect include differences in other lifestyle factors, and access to and quality of care between statin users and non-users. ${ }^{28}$ However, in a previous review of statin use, ${ }^{23}$ this hypothesis was discussed in detail but was not clearly supported by the available data. Specifically, both the uptake and magnitude of the effect from 'healthy actions' such as pneumococcal vaccination were considered insufficient to account for the mortality benefit reported. Our results are consistent with other observational studies ${ }^{15-21}$ in that statin users were comparable in terms of socioeconomic status and ethnicity to non-users. In these circumstances it is hard to attribute the mortality benefit seen with taking statins to differences in access to, or use of, healthcare resources. It is acknowledged that it is not possible for cohort studies to adjust for all potential confounders, and other unidentified confounders may have influenced the results. However, we believe that they are unlikely to explain all of the mortality benefit associated with statin use that we and others have found among COPD patients.

Additional strengths of our study include the length of follow-up, methods defining statin use (prescription dispensing data), and the use of a propensity-matched cohort to further validate our findings. The propensity-matched analysis produced results similar to the unmatched regression. This concordance between the two results suggests that the covariate profile we had assembled contained the important determinants of prognosis for individuals in the cohort, and reduces the likelihood that our results are erroneous due to unknown confounders. Furthermore, this is the only national study to examine outcomes in statin users with COPD compared with non-users with COPD.

\section{Interpretation of findings in relation to previously published work}

This study found a 30\% reduction in all-cause mortality in those prescribed statins, which is comparable to the effect found in previous observational studies. ${ }^{18-21}$ Cause of death data were only available for $56 \%$ of all deaths, and it was not possible to undertake detailed analyses for cause-specific deaths. In addition, this study only captured deaths occurring over a median follow-up of 2.3 years. However, the observation that only $21 \%$ of known deaths were attributed to CVD, in contrast to $48 \%$ for COPD-related and lung cancer-related deaths combined, raises the possibility that statins may be associated with a reduction in deaths from causes other than CVD. Certainly, observational studies of statins in COPD patients to date have reported reductions in COPD-related deaths ${ }^{16}$ and fewer COPD exacerbations. ${ }^{15,17,18}$ Studies have also shown reduced rates of lung cancer ${ }^{29-31}$ and non-pulmonary malignancies among patients treated with statins. ${ }^{32}$ These observations support the hypothesis that a reduction in mortality associated with statin use might be attributable to an alternative biological pathway rather than cholesterol reduction and a reduced incidence of fatal CVD. Indeed, it is well known that statins have much wider actions than their effect on cholesterol - including anti-oxidant, anti-neoplastic (apoptotic), and immune modulating effects ${ }^{11-14}$ - and statins reduce both pulmonary inflammation and systemic inflammation. ${ }^{14} \mathrm{~A}$ detailed review of the pharmacological actions of statins in $\mathrm{COPD}^{14}$ suggests that the wider pleiotrophic effects of statins may explain the reductions in both pulmonary and nonpulmonary-related deaths. However, there are currently no data from randomised controlled trials to prove this hypothesis.

\section{Conclusions}

The results of this study suggest that statin treatment is associated with a reduction in all-cause mortality for patients with COPD. If this is indeed the case, it would represent a significant improvement in outcome for COPD patients who, to date, receive treatments that reduce symptoms only. ${ }^{4-7} \mathrm{~A}$ small randomised controlled trial of statin use in 125 patients with COPD has demonstrated improved exercise tolerance and reduced breathlessness in the treatment group over placebo. ${ }^{33}$ The positive association between statin use and reduced mortality in COPD patients demonstrated in this and other observational studies - together with evidence that many COPD patients have a high absolute CVD risk, that statins appear to suppress lung inflammation, and that statins are well tolerated and cheap - is compelling. However, before statins can be recommended for routine use in patients with COPD, further randomised trial evidence with 'hard' clinical outcomes including favourable changes in exercise capacity and lung function and a favourable incremental cost-effectiveness ratio is likely to be needed. Evidence of benefit from trial data will be necessary to effect widespread changes in clinical practice.

\section{Handling editor Niels Chavannes Statistical review Gopal Netuveli}

Acknowledgements The authors thank Dean Papa for data extraction from databases.

Conflicts of interest The authors declare that they have no conflicts of interest in relation to this article.

Contributorship CMML participated in the design of the study, wrote the first draft of the manuscript and had primary responsibility for publication, planned analysis of the data, participated in interpretation of the analysis, and contributed to discussions. ST participated in the design of the study, co-wrote the first draft of the manuscript, planned analysis of the data, was responsible for data management and performing data analysis, participated in interpretation of the analysis, and contributed to discussions and provided feedback. RY participated in the design of the study, participated in interpretation of the analysis, contributed to discussions and provided feedback. RH contributed to discussions and provided feedback. RM planned analysis of the data, contributed to discussions and provided feedback. WCC participated in the design of the study, participated in interpretation of the 
analysis, contributed to discussions and provided feedback. GJ participated in the design of the study, participated in interpretation of the analysis, contributed to discussions and provided feedback.

Funding Funding was received from a research fund at the School of Population Health, University of Auckland to cover data extraction costs.

\section{References}

1. Broad J, Jackson R. Chronic Obstructive Pulmonary Disease and Lung Cancer in New Zealand. A report commissioned by the Asthma and Respiratory Foundation of New Zealand (Inc.) and the Thoracic Society of Australia and New Zealand, New Zealand Branch. http://www.asthmafoundation.org.nz/files/PDF-files/COPD/ thoracic_rpt_nov2003.pdf, 2003.

2. Tobias M, on behalf of the New Zealand Burden of Disease Study Team. The Burden of Disease and Injury in New Zealand. Wellington: Ministry of Health, 2002.

3. Ministry of Health. Mortality and Demographic Data 2007. Wellington: Ministry of Health, 2010

4. Calverley PMA, Anderson JA, Celli B, et al. Salmeterol and fluticasone propionate and survival in chronic obstructive pulmonary disease. N Engl J Med 2007;356(8):775-89. http://dx.doi.org/10.1056/NEJMoa063070

5. Roche N. Where current pharmacological therapies fall short in COPD: symptom control is not enough. Eur Respir Rev 2007;16(105):98-104. http://dx.doi.org/10.1183/09059180.00010503

6. Spurzem JR, Rennard SI. Pathogenesis of COPD. Semin Respir Crit Care Med 2005; 26(2):142-53. http://dx.doi.org/10.1055/s-2005-869535

7. The Lung Health Study Research Group. Effect of inhaled triamcinolone on the decline in pulmonary function in chronic obstructive pulmonary disease. N Engl J Med 2000;343(26):1902-09. http://dx.doi.org/10.1056/NEJM200012283432601

8. Cazzola M, Ciaprini C, Page CP, Matera MG. Targeting systemic inflammation: novel therapies for the treatment of chronic obstructive pulmonary disease. Expert Opin Ther Targets 2007;11(10):1273-86. http://dx.doi.org/10.1517/14728222.11.10.1273

9. Walsh GM. Statins as emerging treatments for asthma and chronic obstructive pulmonary disease. Exp Rev Resp Med 2008;2(3):329-35. http://dx.doi.org/10.1586/17476348.2.3.329

10. Altose MD. Approaches to slowing the progression of COPD. Curr Opin Pulm Med 2003;9(2):125-30. http://dx.doi.org/10.1097/00063198-200303000-00006

11. Feldman C. The role of statins in respiratory diseases. Clin Pulm Med 2009;16(2):95100. http://dx.doi.org/10.1097/CPM.0b013e31819b3a41

12. Hothersall E, McSharry C, Thomson NC. Potential therapeutic role for statins in respiratory disease. Thorax 2006;61(8):729-34. http://dx.doi.org/10.1136/ thx.2005.057976

13. Liao JK. Clinical implications for statin pleiotropy. Curr Opin Lipidol 2005;16(6):624-9. http://dx.doi.org/10.1097/01.mol.0000191913.16321.60

14. Young RP, Hopkins R, Eaton TE. Pharmacological actions of statins: potential utility in COPD. Eur Respir Rev 2009;18(114):1-11. http://dx.doi.org/10.1183/ 09059180.00005309

15. Blamoun Al, Batty GN, DeBari VA, Rashid AO, Sheikh M, Khan MA. Statins may reduce episodes of exacerbation and the requirement for intubation in patients with COPD: evidence from a retrospective cohort study. Int J Clin Pract 2008;62(9):1373-8. http://dx.doi.org/10.1111/j.1742-1241.2008.01731.x

16. Frost FJ, Petersen $H$, Tollestrup K, Skipper B. Influenza and COPD mortality protection as pleiotropic, dose-dependent effects of statins. Chest 2007;131(4):1006-12. http://dx.doi.org/10.1378/chest.06-1997

17. Keddissi J, Younis WG, Chbeir EA, Daher NN, Dernaika TA, Kinasewitz GT. The use of statins and lung function in current and former smokers. Chest 2007;132(6):1764-71. http://dx.doi.org/10.1378/chest.07-0298

18. Mancini GB, Etminan M, Zhang B, Levesque LE, FitzGerald JM, Brophy JM. Reduction of morbidity and mortality by statins, angiotensin-converting enzyme inhibitors, and angiotensin receptor blockers in patients with chronic obstructive pulmonary disease. $J$ Am Coll Cardiol 2006;47(12):2554-60. http://dx.doi.org/10.1016/j.jacc.2006.04.039

19. Mortensen EM, Copeland LA, Pugh MJ, et al. Impact of statins and ACE inhibitors on mortality after COPD exacerbations. Respir Res 2009;10:45. http://dx.doi.org/10.1186/1465-9921-10-45

20. Soyseth $\mathrm{V}$, Brekke PH, Smith P, Omland T. Statin use is associated with reduced mortality in COPD. Eur Respir J 2007;29(2):279-83. http://dx.doi.org/10.1183/09031936.00106406

21. van Gestel YR, Hoeks SE, Sin DD, et al. Effect of statin therapy on mortality in patients with peripheral arterial disease and comparison of those with versus without associated chronic obstructive pulmonary disease. Am J Cardiol 2008;102(2):192-6. http://dx.doi.org/10.1016/j.amjcard.2008.03.038

22. Dobler CC, Wong KK, Marks GB. Associations between statins and COPD: a systematic review. BMC Pulm 2009;9:32. http://dx.doi.org/10.1186/1471-2466-9-32

23. Young RP, Hopkins R, Eaton TE. Potential benefits of statins on morbidity and mortality in chronic obstructive pulmonary disease: a review of the evidence. Postgrad Med $J$ 2009;85:414-21. http://dx.doi.org/10.1136/pgmj.2008.078477

24. Janda S, Park K, FitzGerald JM, Etminan M, Swiston J. Statins in COPD: a systematic review. Chest 2009;136(3):734-43. http://dx.doi.org/10.1378/chest.09-0194

25. Gelman A, Hill J. Causal inference using regression on the treatment variable. In: Data Analysis Using Regression and Multilevel/Hierarchical Models. New York: Cambridge University Press, 2007.

26. R Development Core Team. R: A language and environment for statistical computing. Vienna: R Foundation for Statistical Computing, 2007.

27. Mannino DM, Watt G, Hole D, et al. The natural history of chronic obstructive pulmonary disease. Eur Respir J 2006;27(3):627-43. http://dx.doi.org/10.1183/09031936.06.00024605

28. Brookhart MA, Patrick AR, Dormuth $C$, et al. Adherence to lipid-lowering therapy and the use of preventive health services: an investigation of the healthy user effect. $A m \mathrm{~J}$ Epidemio/ 2007;166(3):348-54. http://dx.doi.org/10.1093/aje/kwm070

29. Farwell WR, Scranton RE, Lawler EV, et al. The association between statins and cancer incidence in a veterans population. I Natl Cancer Inst 2008;100(2):134-9. http://dx.doi.org/10.1093/jnci/djm286

30. Karp I, Behlouli H, Lelorier J, Pilote L. Statins and cancer risk. Am J Med 2008; 121(4):302-09. http://dx.doi.org/10.1016/j.amjmed.2007.12.011

31. Khurana V, Bejjanki HR, Caldito G, Owens MW. Statins reduce the risk of lung cancer in humans: a large case-control study of US veterans. Chest 2007;131(5):1282-8. http://dx.doi.org/10.1378/chest.06-0931

32. van Gestel YRBM, Hoeks SE, et al. COPD and cancer mortality: the influence of statins. Thorax 2009;64(11):963-7. http://dx.doi.org/10.1136/thx.2009.116731

33. Lee TM, Lin MS, Chang NC. Usefulness of C-reactive protein and interleukin- 6 as predictors of outcomes in patients with chronic obstructive pulmonary disease receiving pravastatin. Am J Cardiol 2008;101(4):530-5.

http://dx.doi.org/10.1016/ j.amjcard.2007.09.102

Available online at $\mathbf{h t t p : / / w w w . t h e p c j . o r g ~}$ 